\title{
A reference-dependent approach to WTP for priority
}

\author{
Gilda-María Hernandez-Maskivker \\ -School of Tourism and Hospitality Management HTSI, Ramon Llull University, Barcelona, \\ Spain
}

Juan L. Nicolau

-J. W. Marriott Professor of Revenue Management, Howard Feiertag Department of Hospitality and Tourism Management, Pamplin College of Business, Virginia Tech, Blacksburg

Gerard Ryan, Mireia Valverde

-Department of Business Management, Faculty of Business \& Economics, Rovira i Virgili University, Reus, Tarragona, Spain

\begin{abstract}
This article introduces the notions of reference dependence and loss aversion to the analysis of waiting times in tourism to examine their effects on people's willingness to pay (WTP). The empirical study carried out using quantile regression confirms that visitors to theme parks who are willing to pay a high price for express passes are reference-dependent (their WTP for an express pass is influenced by the difference between the expected waiting time and the perceived waiting time) and loss averse (a loss in waiting time, i.e. waiting longer than expected, has a greater effect on WTP as this loss is more annoying than an equal-sized gain in waiting time being satisfying). The implications of these findings for the literature on waiting in services are considered.
\end{abstract}

\section{KEYWORDS}

Waiting times, priority, loss aversion, express pass, quantile regression

\section{INTRODUCTION}

Waiting times have been widely explored since the mid 1980s because of the negatives consequences that arise from making consumers wait (Maister, 1985; Rafaeli, Barron, \& Haber, 2002; Unger, Uriely, \& Fuchs, 2016; Wu, Cheng, \& Ai, 2018; Zhang, Li, \& Su, 2017; Zhang, Li, Su, \& Hu, 2017). Customers want to use their time efficiently (Lew \& McKercher, 2006) and they often consider waiting as a waste of time (Leclerc, Schmitt, \& Dubé, 1995). In general, when consumers have to wait, they feel annoyed, irritated and frustrated (Carmon, Shanthikumar, \& Carmon, 1995; Osuna, 1985). From a business standpoint, when customers are made to wait for service, service evaluations and customer satisfaction are lower (Katz, Larson, \& Larson, 1991; Lee \& Lambert, 2000; Li, 2010, pp. 434-437; Taylor, 1995; Yan \& Lotz, 2006). In contrast, when customers are satisfied with waiting times, they are more willing to repurchase and recommend the service to others (Hensley \& Sulek, 2007). 

Volume 71, p. 165-172. DOI https://doi.org/10.1016/.tourman.2018.10.003.

Theme parks are often associated with waiting times and queues (Heger, Offermans, \& Frens, 2009; Nip, 2014). Therefore, managing waiting times is a constant priority of theme park management. Indeed, theme parks employ multiple strategies to reduce delays and enhance the tourist experience (Zhang, Li, Su, et al., 2017). For example, priority lines, widely used by service providers such as airports, supermarkets and public administration, are also used by theme parks. In this way, people who are willing to pay extra may 'jump' or 'skip' the regular queue and enjoy a service with little or no waiting time (Matthew, MacLaren, O'Gorman, \& White, 2012; Tone \& Kohara, 2007). Many well-known theme parks such as Universal Studios, Knott's Berry Farm, Legoland, Port Aventura and Six Flags, have turned to fast line Systems to help solve the problem of waiting times.

In spite of the ongoing efforts made by companies, the reality is that customers are still waiting, so much so that waiting is an all-too common occurrence in theme parks. From a marketing perspective, it is important to understand customer behaviour in order to correctly manage queues and waiting times (Bennett, 1998), and to improve the overall visitor experience (Pearce, 2005, p. 241). In light of the limited consumercentered academic research on priority lines at theme Parks and the need to develop more appropriate and effective waiting solutions, further research on this topic are required. Based on prospect theory (Kahneman \& Tversky, 1979) and analyzing expected and perceived waiting time, this article examines the way tourists behave and make decisions in situations where they have to decide between alternatives that involve uncertainty. In particular, the notions of reference dependence and loss aversion are introduced in the analysis of waiting times in tourism to identify their effects on people's willingness to pay (WTP). This study contributes to the literature as it extends prior research on the trade-off between time and money in the context of waiting times and the different sensitivities to waiting. To be specific, the inclusion of reference points (expected waiting times) and their comparisons to the perceived waiting times allows us to look at the existing different sensitivities from a new angle: visitors who are reference-dependent and loss averse might present different levels of WTP for priority systems.

\section{A REFERENCE-DEPENDENT APPROACH TO WTP FOR EXPRESS PASS}

The literature suggests that markets may be segmented by consumers' sensitivity to waiting times (Friedman \& Friedman, 1997). Several firms, such as Amazon, employ this form of segmentation, offering quicker or slower delivery times according to the customer's WTP or wait (Alotaibi \& Liu, 2012). In this way, customers may exchange time or money in order to achieve their goals (Okada \& Hoch, 2004).

According to prior studies, some customers are not worried about time constraints and they are willing to wait (Riganti \& Nijkamp, 2008). Indeed, they prefer to wait rather than to pay extra money for a faster service (Clark \& Kim, 2007; Matthew et al., 2012). For this group of people, money may be more important than time (Friedman \& Friedman, 1997). In addition, Haynes (1990) explains that waiting becomes more tolerable when customers are conscious that they are saving money with their decision. In this way, Okada and Hoch (2004) suggest that a 'waste of time' may be considered in a more positive way than a 'waste of money'. 

Volume 71, p. 165-172. DOI https://doi.org/10.1016/.tourman.2018.10.003.

Additionally, the literature also shows that there are customers who wish to waste no time waiting or queuing (Giebelhausen, Robinson, \& Cronin Jr, 2011; Larson, 1987). These consumers are willing to pay extra to avoid delays (Matthew et al., 2012) and may be labeled as 'time-hungry' (Setoodeh, 2004). For them, time is akin to money: a scarce and precious good that can be valued in the same way (Haynes, 1990).

As well as customer satisfaction (Oliver, 1980) and service quality (Zeithaml, Leonard, \& Parasuraman, 1993) disconfirmation models are also considered in waiting contexts (Davis \& Heineke, 1998; Durrande Moreau, 1999; Pruyn \& Smidts, 1998; Ryan, Hernandez-Maskivker, Valverde, \& Pamies, 2018; Yan \& Lotz, 2006). In these models, satisfaction is the difference between expectations and perceptions (from a disconfirmation approach) (Davis \& Heineke, 1998; Parasuraman, Zeithaml, \& Berry, 1994). Waiting time disconfirmation is based on comparing customers' expectations and perceptions of waits (Houston, Bettencourt, \& Wenger, 1998; Yan \& Lotz, 2006). Lee and Lambert (2000) suggest that when the perceived waiting time is lower or equal to the expected waiting time, it does not have a negative effect on perceived quality or customer satisfaction (positive disconfirmation). In fact, positive disconfirmation may increase customers satisfaction (Bigné, Andreu, \& Gnoth, 2005). Customers may feel happy with this situation (Lin, Xia, \& Bei, 2015). However, customers may perceive the wait as longer than expected. In this case, people may negatively evaluate their waiting experience (negative disconfirmation). Janakiraman, Meyer, and Hoch (2011) consider expectations and perceptions in a similar manner. They suggest waiting is tolerable when it is shorter than initial waiting expectations and unpleasant when it is longer than expected.

Certainly, when analysing waiting time, it is important to consider that there is an objective waiting time (based on reality), i.e. the realtime customers are waiting, but also there is a subjective waiting time (based on perceptions), i.e. the time customers perceive they are waiting and that may not coincide with real waiting time (Durrande Moreau, 1999).

Companies have different alternatives to manage both of them. On the one hand, they can reduce the real waiting time, for example, by extending the opening hours, opening more checkouts, hiring more employees or implementing new technologies such as machines which sell products or assist customers (Yan \& Lotz, 2006). However, due to operational reasons and the nature of the service, sometimes theme parks cannot avoid waiting times: attractions and rides capacity is exceeded by visitor's demand and queues and delays are unavoidable (Heger et al., 2009; Heo \& Lee, 2009; Matthew et al., 2012). On the other hand, when real waiting time cannot be modified, managers may attempt to reduce the perceived waiting time (subjective waiting time) (Maister, 1985; Pruyn \& Smidts, 1998), which may not match with real waiting times. For instance, a 10-min real waiting time to ride an attraction at a theme park may be perceived as 20 min or 5 min depending on the individual.

As Hornik (1984) explains, in general people tend to overestimate waiting times. Maister's study (1985) shows how, as one of the referents of how to manage perceived waiting times from a service marketing perspective, attempts to understand the psychological component of waiting lines. In order to reduce perceived waiting times and overestimations, companies should fill the wait (Katz et al., 1991; Larson, 1987; Maister, 1985), promote social interaction among waiting customers and/or provide a pleasant and fair waiting environment (Baker \& Cameron, 1996). When customers 

Volume 71, p. 165-172. DOI https://doi.org/10.1016/i.tourman.2018.10.003.

perceive time savings, positive responses appear; however, if they perceive their time is wasted and unexpected waits occur, then negative feelings appear (Lin et al., 2015).

The literature explains that expectations of waiting times should be also managed by firms as they may have a greater influence on the overall wait and service experience (Davis \& Heineke, 1998). For example, companies may manage waiting expectations by informin customers about wait duration (Mishra, Mokhtarian, \& Widaman, 2014; Zhang, Li, Su, et al., 2017). Uncertain waits may lead to high levels of anxiety (Jones \& Peppiatt, 1996). When customers know how long they will have to wait to be served (waiting duration), they tend to feel better and wait with a positive composure (Larson, 1987; Taylor, 1994). When customers have information about the wait, they pay less attention to the passage of time (Hui \& Tse, 1996). Visitors may have certain expectations about waiting times for some services; in light of these waiting expectations and keeping in mind the range of potential negative effects of waiting times, tourists can be more or less willing to pay to avoid waiting.

When customers perceive waiting as a cost and are faced with a choice, Prospect Theory helps to explain customer decisions under a risk (uncertain) waiting situation. This theory developed by Kahneman and Tversky (1979) suggests that the value of time depends on the context and it is not static, considering losses and gains. Authors such as Leclerc et al. (1995) and Lin et al. (2015) have analysed waiting-time decisions in a similar way to monetary decisions, based on Prospect theory. In decisions involving time, people make risk-averse decisions rather than risk-seeking choices (Leclerc et al., 1995). According to Prospect Theory most people prefer obtaining a sure $\$ 100$ rather than taking the risk of a bet in which they might win $\$ 100$ or $\$ 0$; however, people prefer risky options in a choice set in which they might incur a sure lost of $\$ 100$, or they might take a risky bet with a $50 \%$ likelihood of recovering their loss and $50 \%$ of losing $\$ 200$. In the wating time framework, one would expect that saving time (gain) is sought by paying for an express pass as the individuals will get a "sure gain"; however, depending on people's preferences, some individuals might choose to take the risk and just wait in line because, first, the actual wait may not be as long as the expected one, and second, because they would rather sacrifice their time than the money necessary to save that time. To show the intricacies of integrating these elements, Lin et al. (2015) demonstrated that people preferred saving time (gain) in one integrated occasion than saving time in different occasions and they preferred to wait (loss) in different occasions than in one single situation. This is even more intricate if reference points are considered, giving rise to reference dependence and loss aversion.

Reference dependence and loss aversion are two central phenomena in Prospect Theory (Kahneman \& Tversky, 1979). Reference dependence leads people to compare outcomes to reference points rather than just evaluating these outcomes in absolute measures; and loss aversion predicts that the absolute level of a change in demand due to a loss is greater than the corresponding impact of an equal gain.

While these properties have been examined in tourism (Masiero \& Qiu, 2018; Smeral, 2012), they are yet to be studied in the context of waiting time. Regarding reference dependence, people create their expectations about the time they should need to wait before consuming a service; as these expectations become their reference points, when the perceptions of the actual waiting time are observed, people should make comparisons and, if they are reference-dependent, their utility and, in 

Volume 71, p. 165-172. DOI https://doi.org/10.1016/.tourman.2018.10.003.

turn, their WTP for an express pass should be influenced by these comparisons. Therefore, the following hypothesis is stated:

H.1. Willingness to pay for an express pass is influenced by the difference between the expected waiting time and the perceived actual waiting time.

As for loss aversion, observing a loss in waiting time (i.e. perceiving an actual waiting time greater than expected) should be more annoying than an equal-sized gain in waiting time being satisfying (i.e. perceiving an actual waiting time lower than expected). Therefore, loss averse people should be more willing to pay for an express pass that allows them to avoid longer-than-expected waiting times. Consequently, it is hypothesized that:

H.2. Loss averse preferences should increase willingness to pay for an express pass.

\subsection{Control variables}

There are some other dimensions that may have an influence on WTP for an express pass, such as attitudes toward waiting and towards the express pass, customer's prior experiences, age, household size and household income. These dimensions are introduced in the model as control variables.

Attitudes toward waiting and the express pass. Customers can have a more positive and relaxed attitude toward waiting or, in contrast, a more negative attitude (Bennett, 1998; Rose, Evaristo, \& Straub, 2003). There are customers who consider waiting as a waste of valuable time that should be avoided, while others have a positive attitude toward waiting and consider it an opportunity to relax or slow down (Mishra et al., 2014). As attitudes are considered to be the step preceding action (Harrill \& Potts, 2002), visitor's attitudes toward waiting times at theme parks may be a key element when analysing WTP for an express pass. Those who have a negative attitude toward waiting times may be more willing to pay for this service. The literature suggests considering psychosocial variables such as attitudes when predicting customers' behaviours like purchase intentions (Kraus, 1995) or when implementin market segmentation (Voss, Spangenberg, \& Grohmann, 2003). As Ruiz-Molina and Gil-Saura (2008, pp. 306) explain, "attitude refers to a learned predisposition to respond consistently favourably or unfavourably to an object". Positive attitudes toward certain products may be the starting point to stimulate their consumption (Vermeir \& Verbeke, 2006). Thus, a positive or a negative attitude toward an express pass or toward waits may determine customers' purchase decisions. Also, as attitudes are learned, they are the result of prior information and prior experiences (Ruiz-Molina \& Gil-Saura, 2008).

Customer's prior experiences. When customers are faced with a purchase decision, they tend to consider past purchase experiences before they make a decision. Thus, prior experiences may determine a customer's purchase patterns (Lehto, O'Leary, \& Morrison, 2004). People who are accustomed to buy a service may have a higher WTP (Reynisdottir, Song, \& Agrusa, 2008). In contrast, customers without prior experiences may be less likely to purchase the service. Additionally, familiarity with a service or a brand may influence the decision to purchase a service. McGuire and Kimes (2006) 

Volume 71, p. 165-172. DOI https://doi.org/10.1016/.tourman.2018.10.003.

explain that familiarity has to do with going through similar prior experiences over time. In their analysis of customers' familiarity with a specific system to manage queues at restaurants, these authors find that when customers experienced familiarity with the method, positive perceptions, such as fairness, increase.

Age. Some studies on tourist behaviour find that young people demonstrate greater tolerance to waiting times than elderly people, at restaurants (Hwang \& Lambert, 2005) and at theme parks (Ahmadi, 1997). Age may also have an influence on customer's WTP for a service such as an express pass. Although some studies suggest that WTP and age are not related (Anderson, Black, \& Dunn, 1997; Mmopelwa, Kgathi, \& Molefhe, 2007), there are others that explain that WTP for some services may be negatively correlated to age (Arin \& Kramer, 2002; Reynisdottir et al., 2008).

Household size. Fundamentally, household size is a representative aspect of the so-called interpersonal barriers (Crawford \& Godbey, 1987), in such a way that it plays an important and deterrent role in recreational decisions, as large family size restricts vacation spending, such as on express passes.

Household income. According to the literature, income is positively correlated with WTP (Bishai \& Lang, 2000; Halkos \& Matsiori, 2012; Reynisdottir et al., 2008). People with higher incomes have a higher WTP than those with low incomes (Mmopelwa et al., 2007; Reynisdottir et al., 2008). For example, high-income commuters are more willing to pay to reduce their travel time (Mishra et al., 2014). Moreover, people with a higher economic status tend to choose services that offer no waiting time (Clark \& Kim, 2007), as they have a less favourable attitude towards waiting (Mishra et al., 2014). As Kostecki (1996) explains, higher-income individuals generally place a high value on their time, and thus a high cost on waiting and display a high intolerance toward delays. In conclusion, they may be more likely to spend money to avoid waiting (Matthew et al., 2012). In contrast, people with lower levels of income place a lower value on their time and are more relaxed when they need to wait (Bennett, 1998).

Figure 1 shows these relationships that emerge when introducing Prospect Theory into WTP in the context of waiting times: the two central hypotheses -referencedependence and loss aversion-derived from comparing time expectations and time perceptions, and the control variables that give rise to the expectations argued earlier. 
Figure 1. Prospect Theory and WTP in the context of waiting times
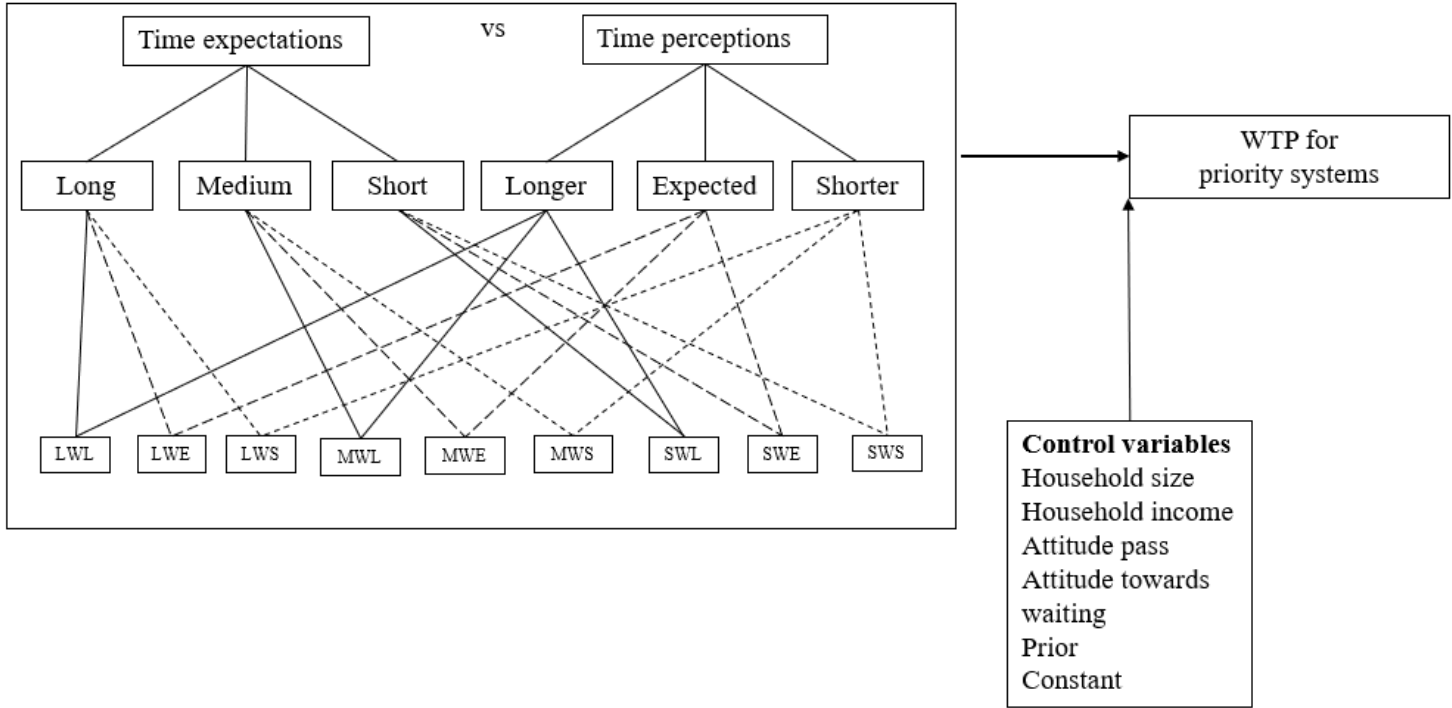

\section{METHODOLOGY}

\subsection{Data analysis}

As in linear regression models (OLS), quantile regression (QR) models try to detect linear relationships between the dependent variable and a set of explanatory variables. OLS, however, seeks to model the conditional mean of the dependent variable, while QR tries to model the conditional $\tau$ th quantile of the dependent variable, where $\tau \in(0$, 1). Consequently, $Q R$ can find potential varying impacts of a determinant factor on the whole range of the dependent variable (i.e., WTP), generally for the 10th, 25th, 50th, 75th, and 90th quantiles. This study uses the OLS estimates as a reference model for comparative purposes to test the superiority of QR over OLS in modeling WTP.

QR is specified as follows (Koenker \& Bassett, 1978): given a random variable $Y$ with probability distribution function $F(y)=\operatorname{Prob}(Y \leq y)$, and considering that $0<\tau<1$, the $\tau$ th quantile of $Y$ is defined as the smallest $y$ that holds $F(y) \geq \tau: Q(\tau)=\inf \{y: F(y) \geq \tau\}$. Taking $n$ observations on $Y$, the empirical distribution function is given by $F_{n}(y)=\sum 1\left(Y_{i} \leq y\right)$, where $1(z)$ is an indicator function that equals 1 if the argument $z$ is true and 0 otherwise. Hence, the empirical quantile is defined as $Q_{n}(\tau)=\inf \{y: F(y) \geq \tau\}$. Expressed from the perspective of an optimization problem:

$$
Q_{n}(\tau)=\arg \min _{\xi}\left\{\sum_{i: Y_{i} \geq \xi} \tau\left|Y_{i}-\xi\right|+\sum_{i: Y_{i}<\xi}(1-\tau)\left|Y_{i}-\xi\right|\right\}=\arg \min _{\xi}\left\{\sum_{i} \rho_{\tau}\left|Y_{i}-\xi\right|\right\}
$$


where $r_{t}(u)=u(\tau-1(u<0))$ is the check function that asymmetrically weights both positive and negative values. Under the assumption of a linear specification for the conditional quantile of the variable "expenses," it is obtained that $Q\left(\tau \mid X_{i}, \beta(\tau)\right)=X_{i}^{\prime} \beta(\tau)$, where $X_{i}$ is the vector of explanatory variables and $\beta(\tau)$ represents the vector of paràmetres linked to the $t$-th quantile. Thus, the optimization problem is:

$$
\hat{\beta}_{n}(\tau)=\arg \min _{\beta(\tau)}\left\{\sum_{i} \rho_{\tau}\left(Y_{i}-X_{i}^{\prime} \beta(\tau)\right)\right\}
$$

Intuitively, the QR estimates are obtained by taking different weights to the absolute residuals, so the whole sample is considered no matter which quantile is estimated.

\subsection{Sample and variable measurement}

Sample. The data collection considered visitors to Port Aventura, the largest theme park in Spain and the second largest in Europe (Anton Clavé, 2010), which has a well known priority system to avoid queues. As there is no official data from the theme park, we conducted the interviews in the surroundings of the theme park. All the individuals who participated in the interview had completed the tour in the park. The questionnaire was made available in Spanish, Catalan, English, French and Russian. A pilot survey was carried out to fully adapt the questionnaire to the conditions of the study area. The principal goal of this pre-test was to check if the questions were understood, if they were well formulated, if any question was difficult to answer or if any important questions were not considered. Four interviewers collected the surveys in June, July and August of 2015 (peak season). The sample consists of 971 individuals. After adjusting for missing values found in the variables used, the final sample size is 506 individuals.

Variable measurement. To analyse reference dependence and loss aversion, two variables are combined, one showing people's expectations of waits and the other the observed waiting time. Specifically, individuals were asked to provide their expectations of the length of their waits (long, medium and short) and their perceived actual waiting time (longer than expected, as expected and shorter than expected), resulting in the following categories: LWL (expecting long waits, perceiving longer than expected); LWE (expecting long waits, perceiving as expected); LWS (expecting long waits, perceiving shorter than expected); MWL (expecting medium waits, perceiving longer than expected); MWE (expecting medium waits, perceiving as expected); MWS (expecting medium waits, perceiving shorter than expected); SWL (expecting short waits, perceiving longer than expected); SWE (expecting short waits, perceiving as expected); and SWS (expecting short waits, perceiving shorter than expected (this category is used as the reference base in the estimation)).

Age is measured through a quantitative variable; household size by the number of people that live in the household; household income per year shows the sum of incomes of all household members. Attitude towards the express passes was measured with a five-point scale (from $1=$ strongly negative to $5=$ strongly positive attitude) in line with Ruiz-Molina and Gil-Saura (2008). Attitude towards waiting times 
are measured through three questions about annoyance, stress and frustration (Bennett, 1998). Each question was measured with a five-point scale (from $1=$ not at all annoying to $5=$ very annoying; from $1=$ not at all stressful to $5=$ very stressful; from $1=$ not at all frustrating to $5=$ very frustrating). A factorial analysis was conducted to group items in a single quantitative variable. As Bennett (1998) suggests in his study about attitude towards queuing at supermarkets, a control question (five-point scale) was also introduced: "In general I really dislike having to wait in queues". This question was included in the questionnaire to obtain a more general, comprehensive measure of "general attitude towards waiting" when applying the factorial analysis. Regarding prior experience, visitors were asked if they had had prior experience with express passes with a dichotomous variable: $1=y e s, 0=$ no. Finally, as for the dependent variables, a quantitative variable measures in euros how much people would be willing to pay for an express pass (WTP).

Table 1 shows the descriptive statistics for the variables used.

Table 1. Descriptive statistics

\begin{tabular}{ccc}
\hline Variable & Mean/Proportion & Standard Deviation \\
\hline LWL & 0.086 & 0.281 \\
LWE & 0.160 & 0.367 \\
LWS & 0.043 & 0.205 \\
MWL & 0.279 & 0.449 \\
MWE & 0.258 & 0.438 \\
MWS & 0.040 & 0.196 \\
SWL & 0.082 & 0.275 \\
SWE & 0.034 & 0.183 \\
Age & 27.68 & 10.61 \\
Household size & 3.336 & 1.284 \\
Household income & 2.417 & 0.926 \\
Attitude pass & 3.351 & 0.967 \\
Attitude towards waiting & -0.001 & 1.000 \\
Prior & 0.313 & - \\
Willingness to pay & 17.11 & 14.71 \\
\hline \hline
\end{tabular}

\section{RESULTS}

Table 2 presents the determinants of WTP, which are estimated at the 10th, 25th, 50th, 75th, and 90th quantiles; the OLS results are also shown as reference. Note that none of the significant parameters have a constant effect over the conditional distribution of the dependent variable; conversely, their impacts vary across quantiles, and are, therefore, different from the OLS estimates.

Regarding the comparisons between the expected and perceived waiting times, the OLS estimates show that reference dependence is confirmed as there are three parameters associated with these comparisons that are significant. Therefore, as the WTP for an express pass is influenced by the difference between the expected waiting time and the perceived waiting time, hypothesis 1 cannot be rejected (this statement will be qualified later when discussing the QR results). Specifically, finding longer than 
expected waits when the visitors are prepared to undergo long or medium waits (LWL and MWL) leads them to increase their WTP. Interestingly, people who are expecting long waits and eventually have shorter than expected (LWS) tend to augment their WTP too. These results imply that, while reference dependence cannot be rejected, loss aversion can only be accepted for medium waits (as before, this partial acceptance of hypothesis 2 will be qualified in the QR results). It seems that in the extremes (long and short expected waits), loss aversion does not emerge to have an impact on the level of WTP: for those expecting long waits the parameters associated with los (LWL) and gains (LWS) are not significantly different $(t=-0.1808 ; p=0.8566)$; the same pattern is observed for those expecting short waits (as SWL is not significant, it means that it is not different from the base alternative (SWS)). Still, it is important to note the qualitatively distinct interpretation of the absence of differences between people expecting long and short waits. Those expecting long waits, no matter whether the perceived wait is longer or shorter than expected, show a higher WTP for an express pass; however, those who expect short waits, regardless of whether the perceived wait is longer or shorter than expected, do not show any inclination towards a higher WTP.

Nevertheless, the results of the quantile estimates allow for richer interpretations and more refined insights. Most of the significant parameters appear for the 75th and 90th quantiles, which show that:

1) reference dependence has an influence on those people willing to pay the maximum. Note that for the 10th, 25th and 50th quantiles, there is only one significant parameter out of twenty-four, so the majority of the significant impacts of reference dependence concentrates around the top WTP (75th and 90th quantiles). Note that, while being confirmed that the difference between the expected and perceived waits has an effect on the WTP for an express pass, this is not general but only on the highest values of WTP (the OLS estimates predict, however, a general effect on the whole range of the dependent variable).

2) for the 75th quantile, loss aversion is not found for those expecting long waits the same as in the OLS estimate- but it is confirmed for those expecting medium and short waits -which is different from the OLS results-.

3) for the 90th quantile, loss aversion is found significant for people that expect long $(\mathrm{t}=2.1350 ; \mathrm{p}=0.0332)$ and medium ( $\mathrm{t}=2.5401 ; \mathrm{p}=0.0114)$ waits, and not significant for short waits. 
Table 2. Determinants of WTP for express pass

(Standar error in parenthesis)

\begin{tabular}{|c|c|c|c|c|c|c|}
\hline Variables & OLS & Q0.1 & Q0.25 & Q0.5 & Q0.75 & Q0.9 \\
\hline LWL & $\begin{array}{l}5.1809^{b} \\
(2.6641)\end{array}$ & $\begin{array}{l}-3.3395 \\
(3.3821)\end{array}$ & $\begin{array}{l}-3.4379 \\
(2.1772)\end{array}$ & $\begin{array}{c}2.3721 \\
(3.0552)\end{array}$ & $\begin{array}{l}10.0602^{\mathrm{b}} \\
(3.9656)\end{array}$ & $\begin{array}{l}14.8700^{\mathrm{b}} \\
(6.9646)\end{array}$ \\
\hline LWE & $\begin{array}{c}2.2165 \\
(1.9864)\end{array}$ & $\begin{array}{l}-4.1813 \\
(3.3524)\end{array}$ & $\begin{array}{l}-3.6756 \\
(1.9494)\end{array}$ & $\begin{array}{c}1.9033 \\
(2.3889)\end{array}$ & $\begin{array}{l}7.0485^{\mathrm{b}} \\
(3.5997)\end{array}$ & $\begin{array}{c}8.6542 \\
(5.4969)\end{array}$ \\
\hline LWS & $\begin{array}{l}5.8746^{\mathrm{b}} \\
(2.7149)\end{array}$ & $\begin{array}{c}3.6697 \\
(3.3626)\end{array}$ & $\begin{array}{c}0.2636 \\
(2.2715)\end{array}$ & $\begin{array}{c}4.3483 \\
(2.8576)\end{array}$ & $\begin{array}{l}8.2666^{\mathrm{b}} \\
(3.2406)\end{array}$ & $\begin{array}{c}6.3726 \\
(4.5673)\end{array}$ \\
\hline MWL & $\begin{array}{l}4.2712^{\mathrm{b}} \\
(1.8503)\end{array}$ & $\begin{array}{l}-4.5139 \\
(3.2970)\end{array}$ & $\begin{array}{l}-3.3174 \\
(1.8446)\end{array}$ & $\begin{array}{c}2.8059 \\
(2.2934)\end{array}$ & $\begin{array}{l}7.5868^{b} \\
(3.0843)\end{array}$ & $\begin{array}{l}16.7023^{b} \\
(6.5752)\end{array}$ \\
\hline MWE & $\begin{array}{c}3.1392 \\
(1.9045)\end{array}$ & $\begin{array}{l}-4.5927 \\
(3.2979)\end{array}$ & $\begin{array}{l}-5.0949^{\mathrm{a}} \\
(1.9306)\end{array}$ & $\begin{array}{c}2.1704 \\
(2.3324)\end{array}$ & $\begin{array}{l}7.6828^{\mathrm{a}} \\
(2.9278)\end{array}$ & $\begin{array}{l}9.9082^{\mathrm{a}} \\
(3.6245)\end{array}$ \\
\hline MWS & $\begin{array}{c}4.6498 \\
(3.6606)\end{array}$ & $\begin{array}{l}-3.9484 \\
(4.1086)\end{array}$ & $\begin{array}{l}-4.4590 \\
(2.7143)\end{array}$ & $\begin{array}{c}0.4689 \\
(3.0202)\end{array}$ & $\begin{array}{c}6.4801 \\
(7.6798)\end{array}$ & $\begin{array}{c}7.4353 \\
(10.5847)\end{array}$ \\
\hline SWL & $\begin{array}{c}4.2744 \\
(2.3569)\end{array}$ & $\begin{array}{l}-3.4063 \\
(3.4144)\end{array}$ & $\begin{array}{l}-2.7323 \\
(2.1903)\end{array}$ & $\begin{array}{c}2.6648 \\
(2.6317)\end{array}$ & $\begin{array}{l}8.1209^{b} \\
(3.9328)\end{array}$ & $\begin{array}{l}10.0555 \\
(5.3628)\end{array}$ \\
\hline SWE & $\begin{array}{l}-1.4327 \\
(2.6338)\end{array}$ & $\begin{array}{l}-0.7174 \\
(4.0619)\end{array}$ & $\begin{array}{l}-1.8867 \\
(2.3980)\end{array}$ & $\begin{array}{c}1.0416 \\
(2.8437)\end{array}$ & $\begin{array}{l}-1.2005 \\
(3.0481)\end{array}$ & $\begin{array}{c}4.8455 \\
(6.8521)\end{array}$ \\
\hline Age & $\begin{array}{l}-0.1157^{b} \\
(0.0532)\end{array}$ & $\begin{array}{l}-0.0172 \\
(0.0336)\end{array}$ & $\begin{array}{l}-0.0794^{b} \\
(0.0336)\end{array}$ & $\begin{array}{l}-0.1261^{\mathrm{a}} \\
(0.0465)\end{array}$ & $\begin{array}{l}-0.1321 \\
(0.0844)\end{array}$ & $\begin{array}{l}-0.1083 \\
(0.1328)\end{array}$ \\
\hline Household size & $\begin{array}{l}-0.6043 \\
(0.4829)\end{array}$ & $\begin{array}{l}-0.2080 \\
(0.4054)\end{array}$ & $\begin{array}{l}-0.0920 \\
(0.3853)\end{array}$ & $\begin{array}{c}0.1187 \\
(0.4045)\end{array}$ & $\begin{array}{c}0.1121 \\
(0.5088)\end{array}$ & $\begin{array}{l}-2.1517^{\mathrm{b}} \\
(0.9375)\end{array}$ \\
\hline Household income & $\begin{array}{c}1.1451 \\
(0.6709)\end{array}$ & $\begin{array}{l}-0.0160 \\
(0.5990)\end{array}$ & $\begin{array}{c}0.5396 \\
(0.5136)\end{array}$ & $\begin{array}{c}0.4944 \\
(0.5425)\end{array}$ & $\begin{array}{c}1.3925 \\
(0.8056)\end{array}$ & $\begin{array}{l}3.5580^{\mathrm{b}} \\
(1.7042)\end{array}$ \\
\hline Attitude pass & $\begin{array}{l}2.7053^{\mathrm{a}} \\
(0.6204)\end{array}$ & $\begin{array}{c}0.7514 \\
(0.4662)\end{array}$ & $\begin{array}{l}2.2827^{\mathrm{a}} \\
(0.4298)\end{array}$ & $\begin{array}{l}2.5823^{\mathrm{a}} \\
(0.4937)\end{array}$ & $\begin{array}{l}3.7183^{\mathrm{a}} \\
(0.9742)\end{array}$ & $\begin{array}{l}4.8180^{b} \\
(1.9787)\end{array}$ \\
\hline Attitude towards waiting & $\begin{array}{l}-1.9005^{a} \\
(0.6771)\end{array}$ & $\begin{array}{l}-0.2174 \\
(0.5106)\end{array}$ & $\begin{array}{l}-0.6270 \\
(0.4597)\end{array}$ & $\begin{array}{l}-1.2004^{b} \\
(0.5275)\end{array}$ & $\begin{array}{l}-1.9768^{\mathrm{b}} \\
(1.0108)\end{array}$ & $\begin{array}{l}-3.6591^{b} \\
(1.6545)\end{array}$ \\
\hline Prior & $\begin{array}{c}7.4043^{\mathrm{a}} \\
(2.3841)\end{array}$ & $\begin{array}{l}4.6044^{\mathrm{b}} \\
(1.8460)\end{array}$ & $\begin{array}{c}6.1148^{\mathrm{a}} \\
(1.1246)\end{array}$ & $\begin{array}{l}4.7565^{\mathrm{a}} \\
(1.2883)\end{array}$ & $\begin{array}{l}4.8701^{\mathrm{b}} \\
(1.9676)\end{array}$ & $\begin{array}{c}7.8389 \\
(4.3426)\end{array}$ \\
\hline Constant & $\begin{array}{c}3.2343 \\
(3.4802)\end{array}$ & $\begin{array}{c}4.0687 \\
(3.2382)\end{array}$ & $\begin{array}{c}3.1966 \\
(2.3780)\end{array}$ & $\begin{array}{c}1.8502 \\
(2.7882)\end{array}$ & $\begin{array}{l}-1.3522 \\
(4.4458)\end{array}$ & $\begin{array}{c}2.1314 \\
(11.7822)\end{array}$ \\
\hline Number of observatons & 506 & 506 & 506 & 506 & 506 & 506 \\
\hline
\end{tabular}

Note: $a=$ prob $<1 \% ; b=$ prob $<5 \%$.

Combining points 2 and 3 , it is found that waiting longer than the expected long waits really has an impact on the highest values of WTP (90th quantile); waiting longer than the expected medium waits has an impact on both 75th and 90th; and waiting longer than the expected short waits does not have an impact on the highest WTP, only on the 75th. Therefore, expectation of waits and how much people value their time, lead them to be willing to pay different amounts. Hypothesis 2 that loss averse 

Volume 71, p. 165-172. DOI https://doi.org/10.1016/.tourman.2018.10.003.

preferences should increase WTP for express pass cannot be rejected, but their effect is contingent upon how long, medium or short the expected waiting time is.

Concerning the control variables, age shows a negative OLS parameter in line with Arin and Kramer (2002) and Reynisdottir et al. (2008). Note, however, that this effect is only found for quantiles 25th and 50th, which means that there is no general effect of age over the whole distribution of WTP. This could explain that some authors such as Anderson et al. (1997) and Mmopelwa et al. (2007) have not found a significant ageWTP relationship as, depending on the variability of WTP in the sample, the effect of age might or might not emerge.

The household size only shows a significant and negative effect for the 90th quantile; thus, households with many members are more reluctant to pay for the maximum amount, but keep neutral when confronted with more reasonable prices.

Household income presents a positive and significant impact for the 90th quantile only, which is in line with the literature (Bishai \& Lang, 2000; Clark \& Kim, 2007; Halkos \& Matsiori, 2012; Reynisdottir et al., 2008). Note that this result suggests that highincome people are willing to pay the most in order to avoid waiting; however, when the WTP amount is not the maximum, it is not affected by income.

Attitudes toward waiting and the express pass are both significant with a negative effect for the former and a positive impact for the latter, as most people seem to consider waiting something to be avoided. Still, these attitudinal effects do not exist for people with low WTP (the 10th quantile in attitude toward express pass and the 10th and the 25th quantiles in attitude toward waiting are not significant). Prior purchase of express passes is significant and positive in line with Reynisdottir et al. (2008) and McGuire and Kimes (2006), all over the distribution of WTP except for the 90th quantile. This means that people with prior experiences with express passes are willing to pay a certain amount of money, yet not the maximum.

\section{CONCLUSIONS}

Waiting is a common component of many tourism services, and people's waiting sensitivity determines their WTP for avoiding the negative effects of waiting times; thus, it comes down to a trade-off between time and money. This article introduces, for the first time in the analysis of waiting times in tourism, the notions of reference dependence and loss aversion. Tourists create their expectations about the waiting times of a service, and these expectations become their reference points; therefore, when the perceived waiting time is observed, they make comparisons and their utility and, consequently, their WTP for a mechanism that helps reduce their waiting times (e.g. an express pass)- should be influenced by these comparisons.

The empirical application carried out in a theme park confirms that visitors to theme parks who are willing to pay a high price for express passes are reference-dependent (as their WTP for an express pass is influenced by the difference between the expected waiting time and the perceived waiting time) and loss averse (as perceiving 

Volume 71, p. 165-172. DOI https://doi.org/10.1016/.tourman.2018.10.003.

an actual waiting time greater than expected brings about a greater effect on their WTP than perceiving an actual waiting time lower than expected). In other words, these results are qualified by the level of WTP, and in particular, reference dependence and loss aversion only show up for the top quantiles (75th and 90th) of the WTP distribution.

The results also show evidence of a negative effect of age (for the central quantiles only), for the rest of the distribution of WTP this variable has a neutral effect; household size only present a negative effect for the top quantile and, consequently no effect for lower levels of WTP; household income has a positive and significant impact for the top quantile only (interestingly, when the WTP amount is not the maximum, it is not affected by income at all); attitudes toward waiting and the express pass have a negative and positive effect, respectively; finally, prior purchase of express passes increases the individual's WTP except for the top level.

Regarding research implications, this study makes an important contribution to research on waiting times. It extends prior research on the trade-off between time and money in the context of waiting times and the different sensitivities to waiting. In particular, the inclusion of reference points (expected waiting times) and their comparisons to the perceived actual waiting times allows us to look at the existing different sensitivities from a new angle: visitors who are reference-dependent and loss averse present a greater WTP for priority systems. Interestingly, note that it seems that these reference dependence and loss aversion properties only activate after a certain point of the WTP distribution.

The results are obtained by using quantile regression. Note that while OLS estimates are taken as the starting point, the use of QR enriches the results and permits the identification of certain intricacies that OLS cannot detect. The use of QR allows us to observe where in the distribution of WTP each variable has an impact and how big it is. Working with the assumption that the effect of a significant parameter is common along the distribution of WTP -as OLS estimates do-could be misleading if such effect varies depending on the level of WTP.

As for implications for practice, the results also have several managerial implications regarding how tourism companies in general and theme parks in particular should elaborate and promote priority systems. Visitors who are reference-dependent and loss averse must be considered high value consumers for theme parks as they are willing to pay the most for an express pass. If theme park's managers are taking crossproduct elasticity into account when designing their segmentation strategy, it is important to recognize that these visitors with these two fundamental tenets of Prospect Theory present top WTP for priority systems, so they are adding extra revenue for theme parks.

For further research, the inclusion of "goal visualization" in the analysis of waiting times in tourism could add new insights to the literature, with important managerial implications. As Cheema and Bagchi (2011) find that allowing consumers to see the end of the line may decrease impatience, letting tourists know about the progress of a waiting line by, for example, setting poles with the remaining minutes, could enhance satisfaction (or reduce dissatisfaction). Also, this goal visualization could alter the reference-dependence and loss aversion patterns found in this study. Further research would also be welcome in terms of how consumers form their expectations of waiting 
times and how these expectations evolve over time and experience with the service in question. Indeed, if expectations are formed by experiences of waiting, any reductions in waiting times achieved by theme parks are likely to increase visitors' subsequent expectations of waiting times for future visits. This suggests that the management of consumer expectations in the context of waiting is a complex issue with important considerations for sales of the high-margin express pass tickets. Finally, keeping in mind that this study was undertaken during peak season, when expectations of long waits are likely to be higher, it may prove insightful to undertake a similar study during an off-peak period associated with expectations of shorter waits. 


\section{Appendix}

Questionnaire

How long did you expect to wait before arriving to the park?

Long waits

Medium waits

Short waits

How would you rate the waiting times at Port Aventura?

Longer than expected

As expected

Shorter than expected

Age

Number of people in household:

Annual household income

Less than $€ 20.000$.

Between $€ 20.000$ and $€ 40.000$.

Between $€ 40.000$ and $€ 80.000$.

More than $€ 80.000$.

My overall attitude towards the express pass systems in general is:

Strongly negative - Negative - Neutral - Positive - Strongly positive.

What is your general attitude towards waiting?

\begin{tabular}{lllllll}
\hline Not at all stressful & 1 & 2 & 3 & 4 & 5 & Very stressful \\
\hline Not at all frustrating & 1 & 2 & 3 & 4 & 5 & Very frustrating \\
Not at all annoying & 1 & 2 & 3 & 4 & 5 & Very annoying \\
\hline
\end{tabular}

Have you ever purchased an express pass in a theme park?

How much would you be willing to pay for an express pass at Port Aventura? 


\section{References}

Ahmadi, R. H. (1997). Managing capacity and flow at theme parks. Operations Research,45(1), 1-13.

Alotaibi, Y., \& Liu, F. (2012). Average waiting time of customers in a new queue System with different classes. Business Process Management Journal, 19(1), 7.

Anderson, G., Black, C., \& Dunn, E. (1997). Willingness to pay to shorten waiting time for cataract surgery. Health Affairs, 16(5), 181-190.

Anton Clavé, S. (2010). Leisure parks and destination redevelopment: the role ofPortAventura, Catalonia. Journal of Policy Research in Tourism, Leisure and Events, 2(1), 67-79.

Arin, T., \& Kramer, R. (2002). Divers' willingness to pay to visit marine sanctuaries: An exploratory study. Ocean \& Coastal Management, 45(2-3), 171-183.

Baker, J., \& Cameron, M. (1996). The effects of the service environment on affect and consumer perception of waiting time: An integrative review and research propositions. Journal of the Academy of Marketing Science, 24(4), 338-349.

Bennett, R. (1998). Queues, customer characteristics and policies for managing waitinglines in supermarkets. International Journal of Retail \& Distribution Management, 26(2), 78-87.

Bigné, J. E., Andreu, L., \& Gnoth, J. (2005). The theme park experience: An analysis of pleasure, arousal and satisfaction. Tourism Management, 26(6), 833-844.

Bishai, D. M., \& Lang, H. C. (2000). The willingness to pay for wait reduction: The disutility of queues for cataract surgery in Canada, Denmark, and Spain. Journal of Health Economics, 19(2), 219-230.

Carmon, Z., Shanthikumar, J. G., \& Carmon, T. F. (1995). A psychological perspective on service segmentation models: The significance of accounting for consumers' perceptions of waiting and service. Management Science, 41(11), 1806-1815.

Cheema, A., \& Bagchi, R. (2011). The effect of goal visualization on goal pursuit: Implications for consumers and managers. Journal of Marketing, 75, 109-123.

Clark, J., \& Kim, B. (2007). Paying vs. waiting in the pursuit of specific egalitarianism. Oxford Economic Papers, 59(3), 486-512. 
Crawford, D. W., \& Godbey, G. (1987). Reconceptualizing barriers to family leisure. Leisure Sciences, 9, 119-128.

Davis, M., \& Heineke, J. (1998). How disconfirmation, perception and actual waiting times impact customer satisfaction. International Journal of Service Industry Management, 9(1), 64.

Durrande Moreau, A. (1999). Waiting for service: Ten years of empirical research. International Journal of Service Industry Management, 10(2), 171-185.

Friedman, H. H., \& Friedman, L. W. (1997). Reducing the "wait" in waiting-line systems: Waiting line segmentation. Business Horizons, 40(4), 54-58.

Giebelhausen, M. D., Robinson, S. G., \& Cronin, J. J., Jr. (2011). Worth waiting for: Increasing satisfaction by making consumers wait. Journal of the Academy of Marketing Science, 39(6), 889-905.

Halkos, G., \& Matsiori, S. (2012). Determinants of willingness to pay for coastal zone quality improvement. The Journal of Socio-economics, 41(4), 391-399.

Harrill, R., \& Potts, T. D. (2002). Social psychological theories of tourist motivation: Exploration, debate, and transition. Tourism Analysis, 7(2), 105-114.

Haynes, P. J. (1990). Hating to wait: Managing the final service encounter. Journal of Services Marketing, 4(4), 20-26.

Heger, C., Offermans, S., \& Frens, J. (2009). Waiting as part of the fun: Interactive gaming in theme park queues. Offermans SAM, Nagtzaam HA H.Proceedings of SIDER: Vol. 9, (pp. 52-55).

Hensley, R. L., \& Sulek, J. (2007). Customer satisfaction with waits in multi-stage services. Managing Service Quality, 17(2), 152-173.

Heo, C. Y., \& Lee, S. (2009). Application of revenue management practices to the theme park industry. International Journal of Hospitality Management, 28(3), 446-453.

Hornik, J. (1984). Subjective vs. Objective time measures: A note on the perception of time in consumer behavior. Journal of Consumer Research, 11(1), 615-618.

Houston, M. B., Bettencourt, L. A., \& Wenger, S. (1998). The relationship between waiting in a service queue and evaluations of service quality: A field theory perspective. Psychology and Marketing, 15(8), 735-753. 

Volume 71, p. 165-172. DOI https://doi.org/10.1016/i.tourman.2018.10.003.

Hui, M., \& Tse, D. (1996). What to tell consumers in waits of different lengths: An integrative model of service evaluation. Journal of Marketing, 60(2), 81-90.

Hwang, J., \& Lambert, C. U. (2005). Customers' identification of acceptable waiting times in a multi-stage restaurant system. Journal of Foodservice Business Research, 8(1), 3-16.

Janakiraman, N., Meyer, R., \& Hoch, S. (2011). The psychology of decisions to abandon waits for service. Journal of Marketing Research, 48(6), 970-984.

Jones, P., \& Peppiatt, E. (1996). Managing perceptions of waiting times in service queues. International Journal of Service Industry Management, 7(5), 47-61.

Kahneman, D., \& Tversky, A. (1979). Prospect theory: And analysis of decision under risk. Econometrica, 47(2), 263-291.

Katz, K. L., Larson, B. M., \& Larson, R. C. (1991). Prescription for the waiting-in-line blues- entertain, enlighten, and engage. Sloan Management Review, 32(2), 44-53.

Koenker, R., \& Bassett, G., Jr. (1978). Regression quantiles. Econometrica: Journal of the Econometric Society, 33-50.

Kostecki, M. (1996). Waiting lines as a marketing issue. European Management Journal, 14(3), 295-303.

Kraus, S. (1995). Attitudes and the prediction of behavior: A meta-analysis of the empirical literature. Personality and Social Psychology Bulletin, 21, 58-75.

Larson, R. C. (1987). Perspectives on queues- social- justice and the psychology of queuing. Operations Research, 35(6), 895-905.

Leclerc, F., Schmitt, B. H., \& Dubé, L. (1995). Waiting time and decision making: Is time like money? Journal of Consumer Research, 110-119.

Lee, W., \& Lambert, C. U. (2000). Impact of waiting time on evaluation of service quality and customer satisfaction in food service operation. Foodservice Research International, 12(4), 241-254.

Lehto, X. Y., Cai, L. A., O'Leary, J. T., \& Huan, T.-C. (2004). Tourist shopping preferences and expenditure behaviours: The case of the Taiwanese outbound market. Journal of Vacation Marketing, 10(4), 320-332.

Lew, A., \& McKercher, B. (2006). Modeling tourist movements: A local destination analysis. Annals of Tourism Research, 33(2), 403-423. 
Li, W. L. (2010). Impact of waiting time on tourists satisfaction in a theme park: An empirical investigation. Proceedings of industrial engineering and engineering management (IEEM) 7-10 Dec. Alaska.

Lin, Y.-T., Xia, K.-N., \& Bei, L.-T. (2015). Customer's perceived value of waiting time for service events. Journal of Consumer Behaviour, 14(1), 28-40.

Maister, D. H. (1985). The psychology of waiting lines. In M. R. S. J. A. Czepiel, \& C. F. Surprenant (Eds.). The service encounter (pp. 113-123). Lexington, MA: Lexington Books.

Masiero, L., \& Qiu, R. T. R. (2018). Modeling reference experience in destination choice. Annals of Tourism Research, 72, 58-74.

Matthew, A., MacLaren, A., O'Gorman, K., \& White, C. (2012). Priority queues: Where social justice and equity collide. Tourism Management, 33(4), 875-884.

McGuire, K. A., \& Kimes, S. E. (2006). The perceived fairness of waitlist-management techniques for restaurants. Cornell Hotel and Restaurant Administration Quarterly, $47(2), 121-134$.

Mishra, G., Mokhtarian, P., \& Widaman, K. (2014). An empirical investigation of attitudes toward waiting on the part of Northern California commuters. Travel Behaviour and Society, 2(2), 78-87.

Mmopelwa, G., Kgathi, D. L., \& Molefhe, L. (2007). Tourists' perceptions and their willingness to pay for park fees: A case study of self-drive tourists and clients for Mobile tour operators in moremi game reserve, Botswana. Tourism Management, 28(4), 1044-1056.

Nip, A. (2014). Waiting times at Hong Kong theme parks rise as tourism increases. South China Morning Post. Retrieved June 11, 2015, from http://www.scmp.com/news/hongkong/article/1413797/waiting-times-hong-kong-themeparks-rise-tourism-increases.

Okada, E. M., \& Hoch, S. J. (2004). Spending time versus spending money. Journal of Consumer Research, 31(2), 313-323.

Oliver, R. (1980). A cognitive model of the antecedents and consequences of satisfaction decisions. Journal of Marketing Research, 17, 460-469.

Osuna, E. E. (1985). The psychological cost of waiting. Journal of Mathematical Psychology, 29(1), 82-105. 
Parasuraman, A., Zeithaml, V., \& Berry, L. (1994). Reassessment of expectations as a comparison standard in measuring service quality: Implications for further research. Journal of Marketing, 58, 111-124.

Pearce, P. L. (2005). Tourist behaviour :themes and conceptual schemes. Clevedon, UK; Buffalo N.Y: Channel View Publications.

Pruyn, A., \& Smidts, A. (1998). Effects of waiting on the satisfaction with the service: Beyond objective time measures. International Journal of Research in Marketing, 15(4), 321-334.

Rafaeli, A., Barron, G., \& Haber, K. (2002). The effects of queue structure on attitudes. Journal of Service Research, 5(2), 125-139.

Reynisdottir, M., Song, H., \& Agrusa, J. (2008). Willingness to pay entrance fees to natural attractions: An Icelandic case study. Tourism Management, 29(6), 1076-1083.

Riganti, P., \& Nijkamp, P. (2008). Congestion in popular tourist areas: A multi-attribute experimental choice analysis of willingness-to-wait in amsterdam. Tourism Economics, 14(1), 25-44.

Rose, G. M., Evaristo, R., \& Straub, D. (2003). Culture and consumer responses to web download time: A four-continent study of mono and polychronism. Engineering Management, IEEE Transactions on, 50(1), 31-44.

Ruiz-Molina, M., \& Gil-Saura, I. (2008). Perceived value, customer attitude and loyalty in retailing. Journal of Retail and Leisure Property, 7, 305-314.

Ryan, G., Hernandez-Maskivker, G., Valverde, M., \& Pamies, M. (2018). Challenging conventional wisdom: Positive waiting. Tourism Management, 64, 64-72.

Setoodeh, R. (2004). Step right up!-amusement-park visitors pay premium to avoid long lines; some have-nots are miffed. Wall Street Journal. Retrieved June 11, 2015, from http://www.wsj.com/articles/SB108959186347560947.

Smeral, E. (2012). International tourism demand and the business cycle. Annals of Tourism Research, 39, 379-400.

Taylor, S. (1994). Waiting for service: The relationship between delays and evaluations of service. Journal of Marketing;Journal of Marketing, 58(2), 56-69.

Taylor, S. (1995). The effects of filled waiting time and service provider control over the delay on evaluations of service. Journal of the Academy of Marketing Science, 23(1), 38-48. 
Tone, T., \& Kohara, K. (2007). A study of the effects of congestion information and a priority boarding pass in a theme park with multi-agents. IEEJ Transactions on Electronics, Information and Systems, 127, 407-415.

Unger, O., Uriely, N., \& Fuchs, G. (2016). The business travel experience. Annals of Tourism Research, 61, 142-156.

Vermeir, I., \& Verbeke, W. (2006). Sustainable food consumption: Exploring the consumer "attitude - behavioral intention" gap. Journal of Agricultural and Environmental Ethics, 19(2), 169-194.

Voss, K., Spangenberg, E., \& Grohmann, B. (2003). Measuring the hedonic and utilitarian dimensions of consumer attitude. Journal of Marketing Research, 40, 310320.

Wu, H. C., Cheng, C. C., \& Ai, C. H. (2018). A study of experiential quality, experiential value, trust, corporate reputation, experiential satisfaction and behavioral intentions for cruise tourists: The case of Hong Kong. Tourism Management, 66, 200-220.

Yan, R., \& Lotz, S. (2006). The waiting game: The role of predicted value, wait disconfirmation, and providers' actions in consumers' service evaluations. Advances in Consumer Research, 33, 412-418.

Zeithaml, V. A., Leonard, L. B., \& Parasuraman, A. (1993). The nature and determinants of customer expectations of service. Journal of the Academy of Marketing Science, 21(1), 1-12.

Zhang, Y., Li, X., \& Su, Q. (2017). Does spatial layout matter to theme park tourism carrying capacity? Tourism Management, 61, 82-95.

Zhang, Y., Li, X., Su, Q., \& Hu, X. (2017). Exploring a theme park's tourism carrying capacity: A demand-side analysis. Tourism Management, 59, 564-578. 